\title{
Long-term trends at the Boknis Eck time series station (Baltic Sea), 1957-2013: does climate change counteract the decline in eutrophication?
}

\author{
S. T. Lennartz ${ }^{1}$, A. Lehmann ${ }^{1}$, J. Herrford ${ }^{1}$, F. Malien ${ }^{1}$, H.-P. Hansen ${ }^{1}$, H. Biester ${ }^{2}$, and H. W. Bange ${ }^{1}$ \\ ${ }^{1}$ GEOMAR Helmholtz Centre for Ocean Research Kiel, Düsternbrooker Weg 20, 24105 Kiel, Germany \\ ${ }^{2}$ TU Braunschweig, AG Umweltgeochemie, Institute of Geoecology, Langer Kamp 19c, 38106 Braunschweig, Germany
}

Correspondence to: S. T. Lennartz (slennartz@geomar.de)

Received: 28 April 2014 - Published in Biogeosciences Discuss.: 27 May 2014

Revised: 30 September 2014 - Accepted: 18 October 2014 - Published: 24 November 2014

\begin{abstract}
The Boknis Eck (BE) time series station, initiated in 1957 , is one of the longest-operated time series stations worldwide. We present the first statistical evaluation of a data set of nine physical, chemical and biological parameters in the period of 1957-2013. In the past three to five decades, all of the measured parameters underwent significant long-term changes. Most striking is an ongoing decline in bottom water oxygen concentration, despite a significant decrease of nutrient and chlorophyll $a$ concentrations. Temperature-enhanced oxygen consumption in the bottom water and a prolongation of the stratification period are discussed as possible reasons for the ongoing oxygen decline despite declining eutrophication. Observations at the BE station were compared with model output of the Kiel Baltic Sea Ice Ocean Model (BSIOM). Reproduced trends were in good agreement with observed trends for temperature and oxygen, but generally the oxygen concentration at the bottom has been overestimated.
\end{abstract}

\section{Introduction}

Long-term observations in oceanography are crucial when it comes to improving the understanding of the state of ecosystems and monitoring their long-term developments. They have been a core strategy in the last 50 decades and are still considered to have high priority today (see e.g. Ducklow et al., 2009), as they enable the quantification of long-term trends, the identification of regime shifts and the characterisation of processes that help to predict future development.
Long-term monitoring is especially important for a dynamic system such as the Baltic Sea, where high variations, which are effective on different timescales, are triggered by natural and anthropogenic causes. The natural hydrographic setting of the Baltic Sea is defined by the small connection to the North Sea, where water exchange takes place through the Danish Straits. The Baltic Sea displays a strong stratification throughout the year, resulting from differences in the salinity of different water masses (Rheinheimer and Nehring, 1995). On a shorter timescale, major saltwater inflows triggered by westerly winds transport large amounts of fully saline North Sea water into the Baltic Sea (Hanninen et al., 2000; Lass and Matthäus, 1996).

Over decadal timescales, anthropogenic influences like eutrophication have been impacting the ecosystem of the Baltic Sea. Marine eutrophication caused by enhanced nutrient input is a widespread phenomenon in coastal areas worldwide, and in the Baltic Sea in particular (HELCOM, 2009). Generally, nutrient concentrations rose until the mid-1980s due to excess riverine input of phosphate and nitrate (Babenerd, 1991; Rosenberg, 1990; HELCOM, 2009), with consequences such as severe deoxygenation (Diaz and Rosenberg, 2008; HELCOM, 2009). The trend in eutrophication and severely rising nutrients has been stopped or even reversed (HELCOM, 2009; Carstensen et al., 2006) since the Helsinki Commission (HELCOM) in 1974 was established to reduce anthropogenic caused marine eutrophication in the Baltic Sea (HELCOM, 1974).

Although the Baltic Sea is one of the best-studied coastal areas (Feistel et al., 2008; BACC, 2008), time series dating 


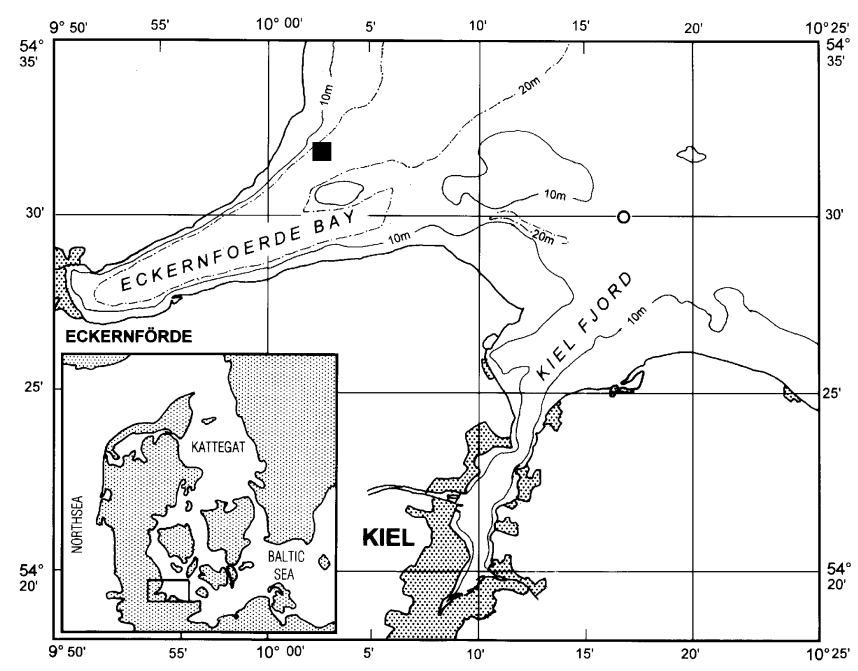

Figure 1. Location of the Boknis Eck time series station at the entrance of Eckernförde Bay in the southwestern Baltic Sea, indicated by the black square. (from Hansen et al., 1999)

back to the 1950 s are sparse. The time series at BE was initiated in 1957 and thus provides continuous information on changes in the southwestern Baltic Sea over more than five decades (Bange et al., 2011). In this study, we present and statistically evaluate a monthly data set of nine physical, chemical and biological parameters observed over a time span of 56 years at Boknis Eck. One focus is the detailed analysis of decadal variability and climatic changes occurring over the entire time span. Decadal climate variability was analysed by evaluating the variation in physical parameters such as temperature, salinity and the density gradient in the water column as an indicator for stability of stratification. The second focus addressed was eutrophication, including the analysis of nutrient and chlorophyll $a$ concentration in the middle of the water column and oxygen content in the bottom water. In a further step, long-term trends were compared to the model output of the Baltic Sea Ice Ocean Model (BSIOM). This approach aims to combine the advantages of both direct measurements and spatially and temporarily highly resolved model output.

\section{Data and methods}

\subsection{Boknis Eck time series station}

The Boknis Eck (BE) time series station is located at the entrance of the Eckernförde Bay $\left(54^{\circ} 31^{\prime} \mathrm{N}, 10^{\circ} 02^{\prime} \mathrm{E} ; 28 \mathrm{~m}\right.$ water depth; Fig. 1) in the southwestern Baltic Sea. The monitoring of a variety of physical, chemical and biological parameters was initiated by Johannes Krey (Institut für Meereskunde, Kiel) in 1957 (Krey et al., 1980), and has been operated since then on a monthly basis with only two ma-

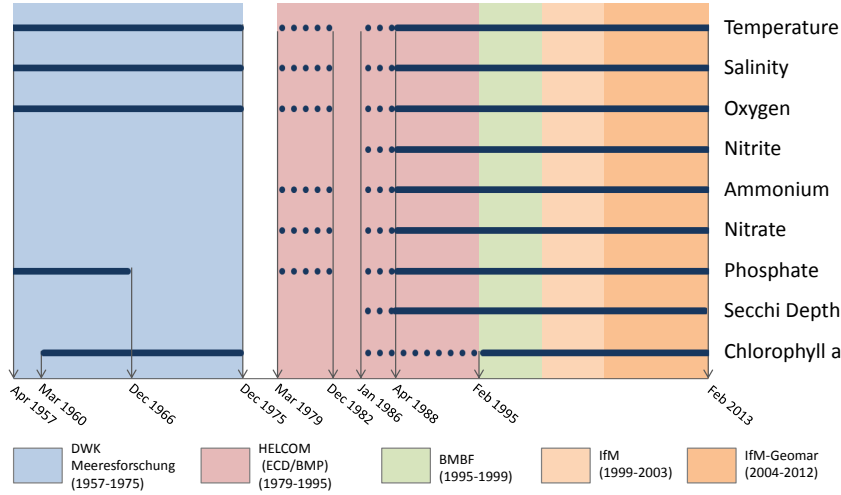

Figure 2. Synopsis of physical, chemical and biological time series at Boknis Eck. Solid lines indicate regular monthly measurements with only up to two following months missing (rare), dotted lines indicate only very irregular measurements with large gaps. Colours represent financial support by different funders. DWK: Deutsche Wissenschaftliche Kommission; HELCOM: Helsinki Commission; BMBF: Bundesministerium für Bildung und Forschung; IfM: Institut für Meereswissenschaften.

jor breaks in 1975-1979 and 1983-1985, where no data are available (Fig. 2).

Starting with measurements of temperature, salinity and oxygen on 30 April 1957, the number of parameters has increased almost continuously. Chlorophyll $a$ (since 1960) and nutrients like nitrate, ammonium (1979), nitrite (1986) and phosphate (1957-1966, since 1979) are now part of the monthly routine (Fig. 2). Measurement techniques changed only once for temperature, salinity, phosphate and chlorophyll $a$ (Table 1), all of which were calibrated so that no shifts in the trends due to a change in measurement techniques are expected. A more detailed summary on the parameters and applied methods can be found in Table 1 and on the Boknis Eck website www.bokniseck.de.

The routine of measurements and analysis has changed little during the observation period. Monthly samples have been taken from research vessels during half-day trips, the sampling usually starting around 09:00 to 10:00 in the morning. Seawater has been sampled at six standard depths $(0.5$ or $1 ; 5,10,15,20 ; 25$ or $26 \mathrm{~m}$ ) using Niskin bottles or the like during several casts, prepared onboard and cooled until further analysis. Analysis was usually carried out in the days following the cruise.

The time series of BE provides a highly valuable data set for three main reasons. Firstly, the time span of observation covers 56 years and hence provides continuous information on changes in the time span of decades. Secondly, there have only been minor changes in the methods used for determining the parameters, and careful calibration avoided shifts or inaccuracies in the data. This consistency strongly enhances the quality of the data, as shifts in the data signals through different methods of analysis can be excluded. Thirdly, the location of Boknis Eck was initially chosen 
Table 1. Synopsis of methods used for determining oceanographic parameters at the Boknis Eck time series station since 1957. n.r.: not reported; CTD: conductivity, temperature, depth; SCFA: segmented continuous flow analyser; Meth.: methanol.

\begin{tabular}{|c|c|c|c|c|}
\hline Parameter & Unit & Method & Reference & Time span \\
\hline \multirow[t]{2}{*}{ Temperature } & ${ }^{\circ} \mathrm{C}$ & Reversing thermometer & Krey et al. (1980) & 1957-1975 \\
\hline & ${ }^{\circ} \mathrm{C}$ & Electrical thermometer, CTD & $\begin{array}{l}\text { HELCOM } \\
\text { Grasshoff et al. (1999) }\end{array}$ & $1979-$ \\
\hline Oxygen & $\mu \mathrm{molL}^{-1}$ & Winkler titration & $\begin{array}{l}\text { Krey et al. (1980) } \\
\text { Grasshoff et al. (1999) }\end{array}$ & 1957- \\
\hline \multirow[t]{2}{*}{ Salinity } & $\%$ & Refractometer & Krey et al. (1980) & 1957-n.r. \\
\hline & psu & Salinometer, CTD & Krey et al. (1980) & n.r.- \\
\hline Phosphate & $\begin{array}{l}\mu \mathrm{gL}^{-1} \\
\mu \mathrm{molL}^{-1}\end{array}$ & $\begin{array}{l}\text { Photometer ELKO Zeiss II } \\
\text { SCFA }\end{array}$ & $\begin{array}{l}\text { Grasshoff et al. (1999) } \\
\text { Grasshoff et al. (1999) }\end{array}$ & $\begin{array}{l}1957-7 / 1970 \\
8 / 1970-\end{array}$ \\
\hline Nitrate & $\mu \mathrm{mol} \mathrm{L}^{-1}$ & SCFA & Grasshoff et al. (1999) & 1979- \\
\hline Nitrite & $\mu \mathrm{mol} \mathrm{L}^{-1}$ & SCFA & Grasshoff et al. (1999) & 1979- \\
\hline Ammonium & $\mu \mathrm{mol} \mathrm{L}^{-1}$ & SCFA & Grasshoff et al. (1999) & $1986-$ \\
\hline \multirow[t]{2}{*}{ Chlorophyll $a$} & $\mu g \mathrm{~L}^{-1}$ & Meth. extraction, photometer & Krey (1939) & 1975-2009 \\
\hline & $\mu g \mathrm{~L}^{-1}$ & Fluorometer & Welschmeyer (1994) & $2009-$ \\
\hline Secchi depth & $\mathrm{m}$ & Secchi disc & Tyler (1968) & 1986- \\
\hline
\end{tabular}

because it reflects the hydrographic setting of the Kiel Bight (Krey et al., 1980). As there are no major rivers discharging into the Eckernförde Bay, riverine inputs of, for example, nutrients can be neglected; however, influences by direct runoff from land cannot be excluded.

\subsection{Statistical analysis}

The complete time series of nine parameters covering the period from 1957 to 2013 is described and statistically evaluated for the first time. Statistical tests covering the long-term development of median (Mann-Kendall test (MKT), Sen's slope) and extreme values (quantile regression of the 10th and 90th percentile) were applied (for details, see below). Prior to the analysis, data were averaged as sampling was conducted at slightly different standard depths (differences $1 \mathrm{~m}$ ) or additional depths in the described period. Thus, data were averaged to the following ranges: $0-2.5,3-7.5,8-12.5$, $13-17.5 \mathrm{~m}, 18-22.5$ and $>23 \mathrm{~m}$. The ranges are referred to as 1, 5, 10, 15, 20 and $25 \mathrm{~m}$. For the MKT and for descriptive statistics, the averaged raw data including irregular spacing and missing values were used.

The measurements were averaged in cases of several dates per month $(<5 \%)$ and assumed to be representative of the whole month. Therefore, the corresponding date was chosen to be the middle of the month (the 15th). Gaps were filled by linear interpolation in the case of one or two missing months in a row; larger gaps were filled by replacement with the median of the corresponding month. In the case of missing values, the temperature at the surface $(1 \mathrm{~m})$ was replaced by the model output of the Baltic Sea Ice Ocean Model (Lehmann et al., 2014).

Besides the measured parameters, oxygen saturation and density gradient were derived from measurements. Density was calculated using the UNESCO algorithm for density in seawater (UNESCO, 1981). Oxygen saturation was calculated according to Eq. 1, with the measured concentration $C_{\mathrm{m}}$ and the equilibrium concentration $C_{\mathrm{a}}$ according to Garcia and Gordon (1992) using temperature and salinity from the BE time series:

$\operatorname{Sat}_{\mathrm{oxy}}[\%]=\frac{C_{\mathrm{m}}}{C_{\mathrm{a}}} \cdot 100$.

The nutrient concentrations at $10 \mathrm{~m}$ depth were treated differently than the physical parameters due to their different seasonality. As nutrients become limiting during summer (Wasmund et al., 2011), their concentration is very low between March and September and does not show large variations. A general method to decipher trends in nutrients is to consider the means of December-January-February (DJF) for each winter period, which were simply linearly regressed. Phosphate and ammonium were additionally analysed in the bottom layer, using the monthly MKT for each month individually.

\subsubsection{Mann-Kendall test}

The Mann-Kendall test (MKT) is a nonparametric, statistical test to decipher significant monotonic long-term trends in time series. The MKT tests the null hypothesis that all variables are randomly distributed against the alternative hypothesis that a monotonic trend exists in the time series on a given significance level $\alpha$ (here $\alpha=0.05$ ). The test statistics of the MKT can be found in Hirsch and Slack (1984).

The MKT can be modified to decipher trends in seasonal data, e.g. monthly data like the BE time series, when a homogeneous trend is present (Hirsch and Slack, 1984). A seasonal MKT including all seasons was performed when trends 

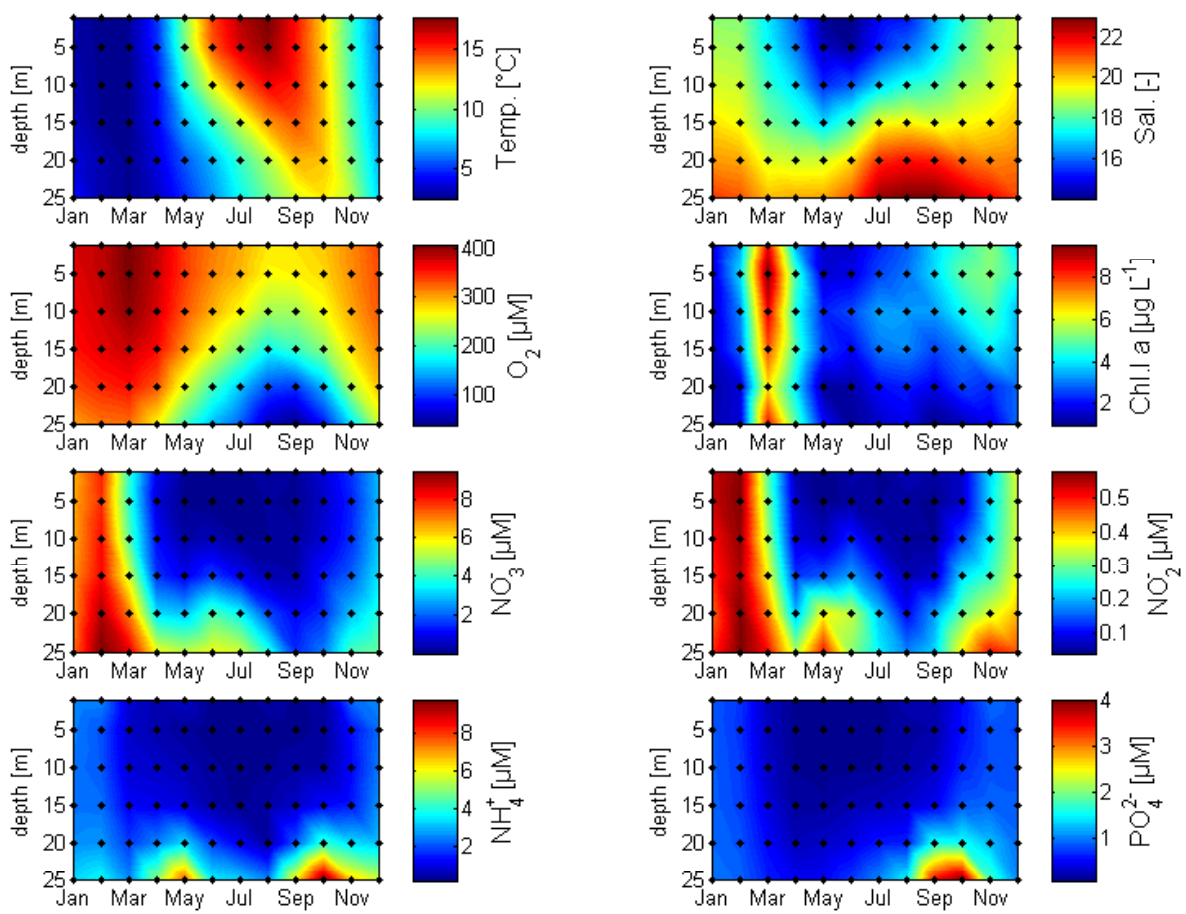

Figure 3. Mean seasonal cycle of temperature (1957-2013), salinity (1957-2013), oxygen (1957-2013), chlorophyll $a$ (1960-2013), nitrate (1979-2013), nitrite (1986-2013), ammonium (1979-2013) and phosphate (1957-2013). The black dots indicate location (at six standard depths) and time (12 months) of measurements taken into account for interpolation.

in the individual months were homogeneous; otherwise the months were tested individually.

If a trend is present in the time series according to the MKT, a median slope was computed according to Sen (1968). The MKT test was applied to the raw data including missing and tied values, and the latter were averaged within the MKT function. For the test, a MatLab function from Burkey (2012) based on the MKT accounting for serial correlation by Hirsch and Slack (1984) and Sen (1968) was used.

\subsubsection{Quantile regression}

The decrease or increase in extreme values within the time series was evaluated by quantile regression, which is a leastsquares optimisation technique to find the conditional quantile in a time series (Koenker and Hallock, 2001).

To assess the significance of the trend, the method proposed by Franzke (2013) was applied, using a constrained Monte Carlo approach to generate surrogate data. Quantile regression was then applied to each of the surrogate data sets. A statistically significant trend was present if the trend in the original time series lay outside of the $95 \%$ boundaries of the trends for the surrogate data, which equals a level of significance of $\alpha=0.1$ (two-sided). The surrogate data were generated by following an approach of Schreiber and Schmitz (1996). They proposed an iterative algorithm that generates time series with the same power spectrum and the same range of values. Details can be found in their paper, and are only briefly summarised here: surrogate data were generated by (i) Fourier transforming and randomly shuffling of the original time series, (ii) replacing the amplitudes of the old time series with the new one and Fourier transforming it inversely afterwards, (iii) rank ordering of the new time series according to the value spectrum of the old time series, and (iv) repeating steps (ii) and (iii) until convergence.

Following this approach, 500 surrogate time series were generated. As the generation of the surrogate data required complete time series, both the quantile regression and the generation of the data sets were performed with the interpolated and gap-filled time series.

\subsection{Hydrodynamic model of the Baltic Sea}

The numerical model used in this study is a threedimensional coupled sea-ice ocean model of the Baltic Sea (BSIOM; Lehmann and Hinrichsen, 2000; Lehmann et al., 2002). The horizontal resolution of the coupled sea-ice ocean model is at present $2.5 \mathrm{~km}$, and 60 levels are specified in the vertical, which enables the upper $100 \mathrm{~m}$ to be resolved into levels of $3 \mathrm{~m}$ thickness. The model domain comprises the Baltic Sea, including the Kattegat and the Skagerrak. At the western boundary, a simplified North Sea basin is connected to the Skagerrak to supply characteristic North Sea 

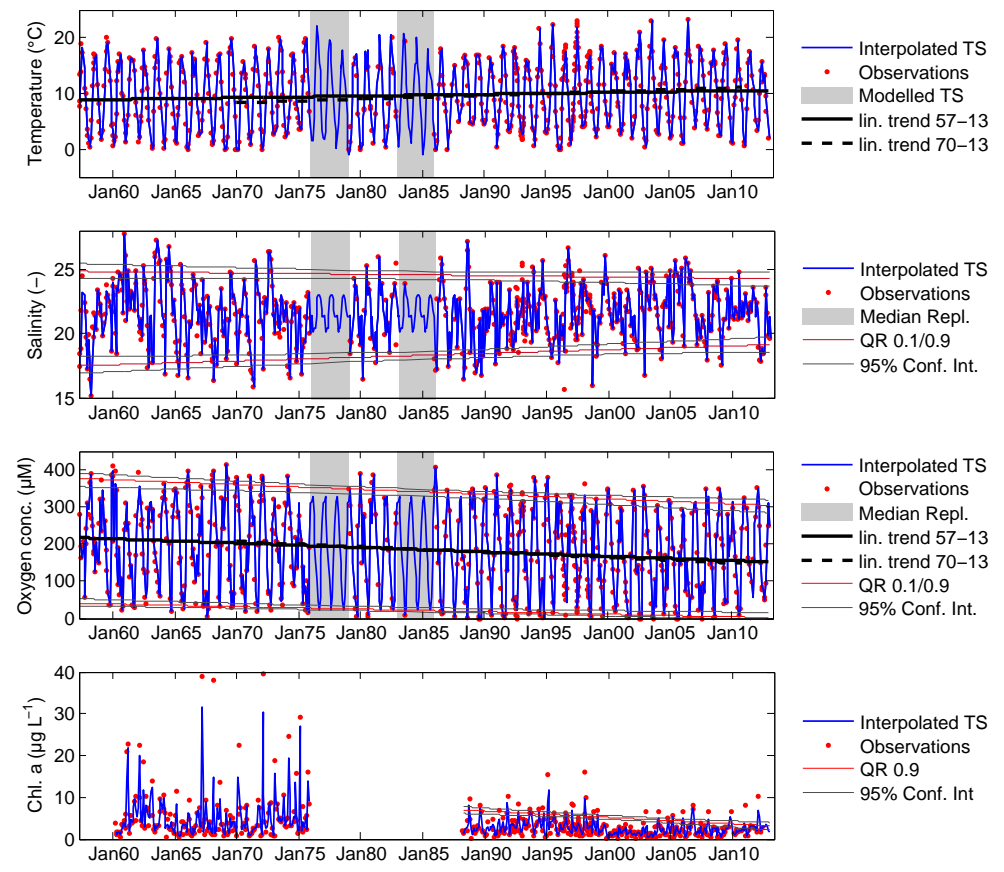

Figure 4. Time series of temperature $(1 \mathrm{~m})$, salinity $(25 \mathrm{~m})$, oxygen $(25 \mathrm{~m})$ and chlorophyll $a$ concentration $(10 \mathrm{~m})$. Shown are various statistical results discussed in Sect. 3, e.g. quantile regression (QR) or linear trends over different time spans. TS: time series; Median Repl.: median replacement; Conf. Int.: confidence interval of quantile regression; Chl. $a$ : chlorophyll $a$.

water masses in terms of temperature and salinity profiles resulting from the different forcing conditions (Lehmann, 1995). Prescribed low-frequency sea level variations in the North Sea/Skagerrak were calculated from the BSI (Baltic Sea index; Lehmann et al., 2002; Novotny et al., 2006). The coupled sea-ice ocean model is forced by realistic atmospheric conditions taken from the Swedish Meteorological and Hydrological Institute (SMHI Norrköping, Sweden) meteorological database (L. Meuller, personal communication), which covers the whole Baltic drainage basin on a regular grid of $1^{\circ} \times 1^{\circ}$ with a temporal increment of $3 \mathrm{~h}$. The database consists of synoptic measurements that were interpolated on the regular grid with a two-dimensional optimum interpolation scheme. This database, which for modelling purposes was further interpolated onto the model grid, includes surface pressure, precipitation, cloudiness, air temperature and water vapour mixing ratio at $2 \mathrm{~m}$ height, and geostrophic wind. Wind speed and direction at $10 \mathrm{~m}$ height were calculated from geostrophic winds with respect to different degrees of roughness on the open sea and off the coast (Bumke et al., 1998). BSIOM forcing functions, such as wind stress, radiation and heat fluxes were calculated according to Rudolph and Lehmann (2006). Additionally, river runoff was prescribed from a monthly mean runoff data set (Kronsell and Andersson, 2012). The numerical model BSIOM has been run for the period 1970-2010.

The oxygen consumption sub-model (OXYCON; Hansen and Bendtsen, 2009; Jonasson et al., 2012) describes one pelagic oxygen sink and two benthic sinks due to microbial and macrofaunal respiration. Pelagic and benthic oxygen consumption is modelled as a function of temperature and oxygen concentration. Originally, Hansen and Bendtsen (2009) developed OXYCON for the North Sea-Baltic Sea transition area including the Kattegat and the Belt Sea. They estimated an annual average of primary production to be $160 \mathrm{~g} \mathrm{C} \mathrm{m}^{-2}$ for this area (Bendtsen and Hansen, 2013). However, a constant rate of primary production is not suitable when simulating the entire Baltic Sea. Wasmund et al. (2001) compiled primary production data resolved for the different sub-basins of the Baltic Sea, covering two time periods around 1970-1980 and 1990-2000, respectively. Over the period of about 20 years, primary production nearly doubled in almost all regions of the Baltic Sea. According to these changes in primary production, oxygen consumption rates were linearly increased from 1970 until 1997, and kept constant afterwards. At the sea surface, the oxygen flux is based on the oxygen saturation concentration determined from the modelled sea surface temperature and salinity values. The BSIOM-OXYCON model is extensively validated in Lehmann et al. (2014).

For comparison, mean values of the water column in both measured and modelled parameters were compared. Averaging was necessary as the model had a higher spatial resolution than the sampling. Model output for the Boknis Eck station on the day of sampling was compared to the 
Table 2. Test statistics of monthly Mann-Kendall tests part I. Only significant results are shown. Tau $b$ : Kendall coefficient for time series including ties; Sen's slope: median slope present in time series $\left(\mathrm{yr}^{-1}\right)$; C.I.: confidence interval of Sen's slope.

\begin{tabular}{|c|c|c|c|c|c|}
\hline & Tau $b$ & $p$ value & Sen's slope & C.I. $5 \%$ & C.I. $95 \%$ \\
\hline \multicolumn{6}{|c|}{ Temperature $1 \mathrm{~m}\left({ }^{\circ} \mathrm{C}\right)$} \\
\hline Jan & 0.21 & $0.048^{1}$ & 0.03 & 0 & 0.05 \\
\hline Apr & 0.35 & $<0.001$ & 0.07 & 0.03 & 0.10 \\
\hline May & 0.30 & 0.003 & 0.06 & 0.02 & 0.09 \\
\hline \multicolumn{6}{|c|}{ Temperature $25 \mathrm{~m}\left({ }^{\circ} \mathrm{C}\right)$} \\
\hline Jan & 0.23 & 0.026 & 0.03 & 0.00 & 0.06 \\
\hline Feb & 0.20 & 0.044 & 0.03 & 0.00 & 0.06 \\
\hline Mar & 0.22 & 0.016 & 0.03 & 0.01 & 0.06 \\
\hline Apr & 0.31 & 0.001 & 0.04 & 0.02 & 0.06 \\
\hline Jun & 0.23 & 0.026 & 0.03 & 0.00 & 0.05 \\
\hline Sep & 0.25 & 0.005 & 0.04 & 0.01 & 0.06 \\
\hline \multicolumn{6}{|c|}{ Salinity $(-)$} \\
\hline Mar & 0.19 & 0.037 & 0.04 & 0.00 & 0.07 \\
\hline Apr & 0.23 & 0.011 & 0.06 & 0.01 & 0.10 \\
\hline \multicolumn{6}{|c|}{ Oxygen concentration $25 \mathrm{~m}(\mu \mathrm{M})$} \\
\hline Jan & -0.27 & 0.011 & -1.45 & -2.42 & -0.33 \\
\hline Mar & -0.29 & 0.002 & -1.18 & -1.96 & -0.46 \\
\hline Apr & -0.31 & 0.001 & -1.63 & -2.46 & -0.69 \\
\hline May & -0.27 & 0.006 & -1.20 & -2.35 & -0.37 \\
\hline Jul & -0.34 & $<0.001$ & -1.51 & -2.22 & -0.79 \\
\hline Aug & -0.20 & 0.030 & -0.71 & -1.32 & -0.08 \\
\hline Sep & -0.35 & $<0.001$ & -0.76 & -1.31 & -0.36 \\
\hline \multicolumn{6}{|c|}{ Oxygen saturation $(\%)$} \\
\hline Jan & -0.23 & 0.032 & -0.26 & -0.52 & -0.02 \\
\hline Apr & -0.26 & 0.005 & -0.33 & -0.56 & -0.15 \\
\hline May & -0.24 & 0.016 & -0.32 & -0.59 & -0.06 \\
\hline Jul & -0.32 & 0.001 & -0.47 & -0.71 & -0.23 \\
\hline Sep & -0.32 & 0.001 & -0.22 & -0.39 & -0.10 \\
\hline \multicolumn{6}{|c|}{ Density gradient $\left(\mathrm{kg} \mathrm{m}^{-4}\right)$} \\
\hline Apr & 0.32 & 0.001 & 0.002 & 0.001 & 0.003 \\
\hline Jul & -0.19 & 0.043 & -0.001 & -0.002 & $>-0.001$ \\
\hline Oct & -0.21 & 0.038 & -0.001 & -0.003 & $>-0.001$ \\
\hline \multicolumn{6}{|c|}{ Chlorophyll $a$ I $10 \mathrm{~m}\left(\mu \mathrm{gL}^{-1}\right)$} \\
\hline Feb & -0.50 & 0.016 & -0.30 & -0.70 & -0.06 \\
\hline \multicolumn{6}{|c|}{ Chlorophyll $a$ II $10 \mathrm{~m}\left(\mu \mathrm{gL}^{-1}\right)$} \\
\hline Feb & 0.30 & 0.021 & 0.06 & 0 & 0.22 \\
\hline Apr & -0.38 & 0.002 & -0.11 & -0.19 & -0.03 \\
\hline May & -0.33 & 0.018 & -0.04 & -0.09 & -0.01 \\
\hline Jul & -0.29 & 0.017 & -0.04 & -0.12 & -0.01 \\
\hline Oct & -0.30 & 0.031 & -0.12 & -0.23 & -0.01 \\
\hline
\end{tabular}

measurements by means of linear regression and the deviation from the bisectrix in the regression plot.

Furthermore, linear regression was performed with daily as well as monthly (day of BE observations) model output to assess the trends in modelled temperature, salinity and oxygen content. These were compared to the linear regression of the monthly observation of these three parameters at Boknis Eck.

To test the hypothesis of altered stratification, the development of the thermocline was further investigated with the model output of the BSIOM. Different criteria in temperature difference across the thermocline were applied and the trend in the length of the stratification period was assessed via linear regression.

\section{Results}

\subsection{Long-term trends in the BE time series}

\subsubsection{Temperature}

Surface temperature was dominated by a clear seasonal cycle (Fig. 4). However, the cycles at different depths were asynchronous; thus a thermal gradient and consequently a stratification in the water column occurred. During the period 1957 to 2013, the months January to March exhibited an almost homogenously tempered water column. A thermocline usually developed in March/April and lasted until October at a depth of 10 to $15 \mathrm{~m}$ (Fig. 3).

Temperature significantly increased in January, April and May, with rising trends between 0.03 and $0.06^{\circ} \mathrm{C} \mathrm{yr}^{-1}$ (Table 2). The increase was $0.018^{\circ} \mathrm{Cyr}^{-1}$, but was not significant. Testing for trends in the extreme values, e.g. the 10 and $90 \%$ quantile, yielded positive tendencies for both quantiles, but they were not significant ( $p>0.05$, Table 4$)$. Tendencies in extreme values and mean were similar.

The temperature distributions for August, usually the warmest month in a year, revealed that warmer temperature anomalies increased in frequency during the second half of the series from 1985 onwards (Fig. 6). Anomalies of up to $+2.2^{\circ} \mathrm{C}(1997,2003)$ occurred, while the mean did not shift significantly.

The temperature at $25 \mathrm{~m}$ showed a similar strong annual cycle as the surface, but the warming pattern was different. Highest temperatures usually occurred in October, and lowest during February. Warming tendencies could be detected for all months, with significant warming in the period January to April as well as for June and September (Table 2).

\subsubsection{Salinity}

The bottom water salinity at $25 \mathrm{~m}$ depth displayed strong fluctuations (Fig. 4) but did not have a regular annual cycle. The mean salinity was $26.6 \pm 2.0$ and varied in a mean range of 2.9. The high bottom salinity indicates an origin from the Kattegat surface water, which enters the Danish Straits as a dense bottom current. The bottom water moves to the south, through the Little and Great Belt, entering the Kiel Bight from the north and east, finally arriving at Eckernförde Bay. On average, the lowest salinity was present in March and the highest in August and September, but there was variation in the timing of the maxima and minima. A halocline is present throughout the year, with stronger gradients in summer (March-October, Fig. 3).

No significant trend was detectable with the seasonal MKT for salinity in the period from 1957 to 2013 (Table 4), although short-term variations were present over a relatively large range (about $22 \%$ ). However, salinity increased slightly but significantly by $0.04 \mathrm{yr}^{-1}$ (March) and $0.06 \mathrm{yr}^{-1}$ (April) (Table 2). Negative tendencies were present in the 

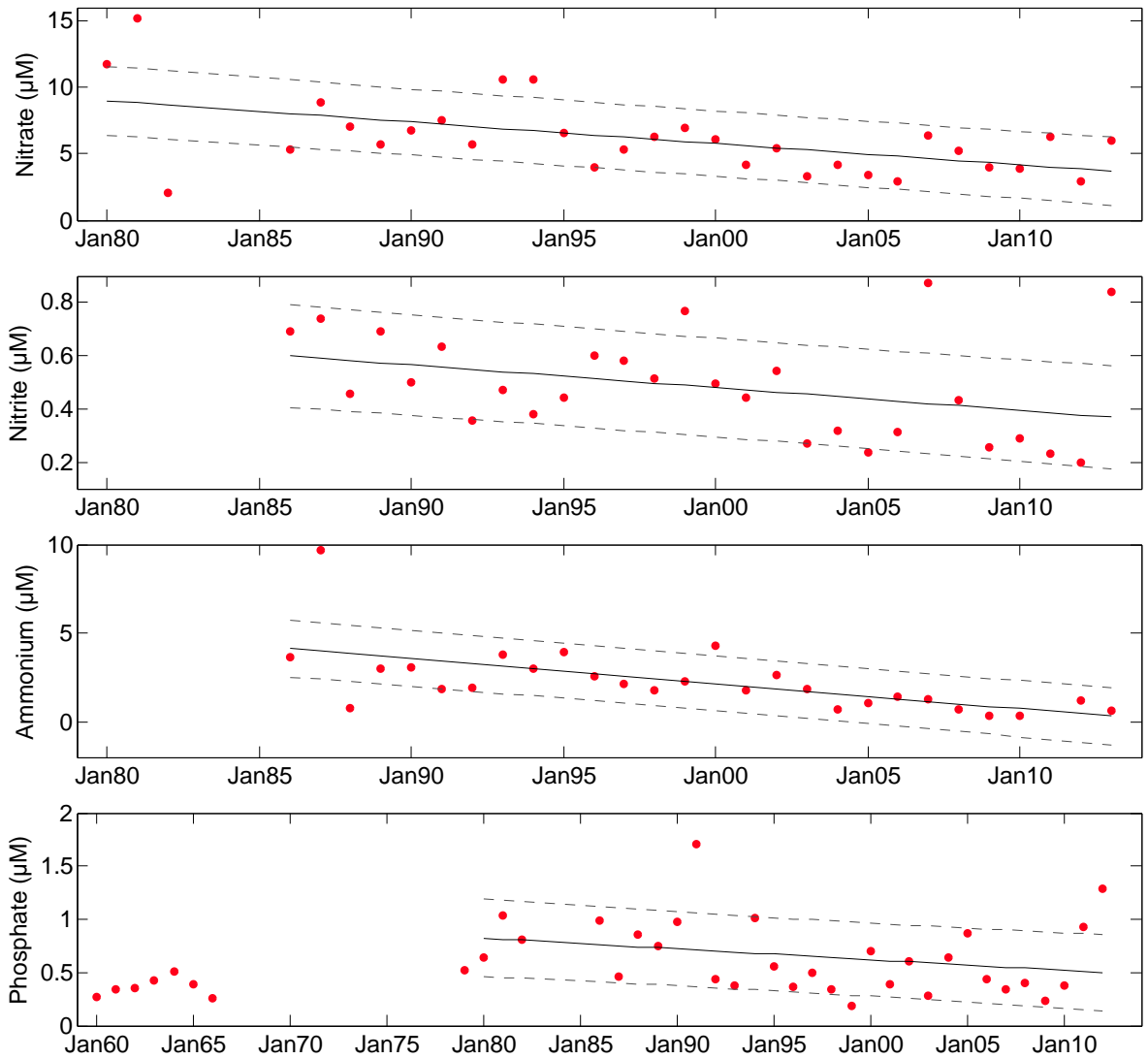

Figure 5. Average winter concentration (December-January-February, DJF, red dots) of nutrients at the Boknis Eck time series station, as well as linear decreasing trends (solid line represents the linear trend, broken lines the $95 \%$ confidence interval). Note the different $x$ axis for phosphate.

period between July and October, but these were not significant. All other tendencies were positive but also not significant. Testing for a trend in extreme values revealed a significant increase in the $10 \%$ quantiles $\left(+0.025 \mathrm{yr}^{-1}\right)$ (Table 4$)$. The correlation between oxygen and salinity in the bottom water was not significant at the $\alpha=0.05$ level.

\subsubsection{Oxygen}

Oxygen concentration at $25 \mathrm{~m}$ depth was dominated by an annual cycle, with the highest concentration in March and the lowest in September (Fig. 4). They were decreasing with a median slope (Sen's slope) of $-0.9 \mu \mathrm{molL}^{-1} \mathrm{yr}^{-1}$ (Table 4). To better resolve the trends for individual months, the MKT was conducted for each month individually. A significant decreasing trend could be detected in January and for the summer months from April to September in a range of $-0.5 \mu \mathrm{molL}^{-1} \mathrm{yr}^{-1}$ (July) and $-0.8 \mu \mathrm{molL}^{-1} \mathrm{yr}^{-1}$ (April) (Table 2). The concentrations of the $10 \%$ quantile significantly decreased as well, with a similar intensity of $-0.78 \mu \mathrm{molL}^{-1} \mathrm{yr}^{-1}$ (Table 4). The number of anoxic and suboxic events (here $<10 \mu \mathrm{molL}^{-1} \mathrm{O}_{2}$ ) has increased continuously since the 1970s (Fig. 7).
Similar trends were found in oxygen saturation calculated from measured oxygen concentrations, temperature and salinity (Eq. 1). Monthly MKT for oxygen saturation yielded a significant decrease in January, April, May, July and September in a range of $-0.26 \% \mathrm{yr}^{-1}$ (January) to $-0.47 \% \mathrm{yr}^{-1}$ (July) (Table 2).

\subsubsection{Density gradient}

The density gradient varied seasonally with minima during winter and maxima during summer months. Significant trends could be found for three months: the highest significant increase was found in April, when the gradient rose by $0.002 \mathrm{~kg} \mathrm{~m}^{-4} \mathrm{yr}^{-1}$. Significant negative but weaker trends were detected in July and October (both $-0.001 \mathrm{~kg} \mathrm{~m}^{-4} \mathrm{yr}^{-1}$ ) (Table 2).

\subsubsection{Phosphate}

The phosphate concentration in the middle of the water column (10 m depth) displayed regular seasonal dynamics throughout the whole sequence, i.e. 1957 to 2013 (despite the major gap in measurements from 1966 to 1986). During the 


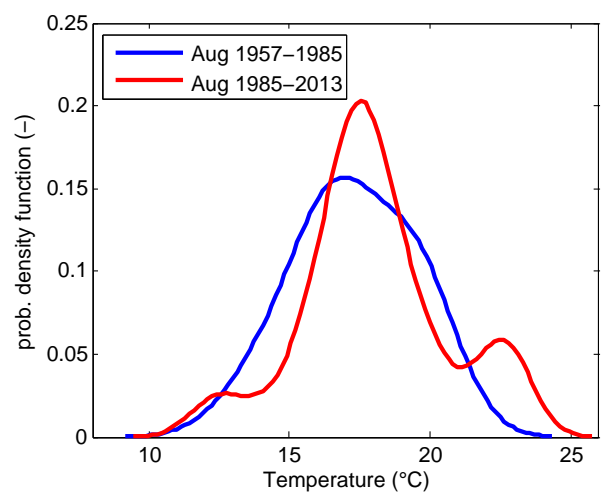

Figure 6. Normalised temperature distribution for observations at $\mathrm{BE}$ in August for the first half (blue) and the second half (red) of the time series at the surface water $(1 \mathrm{~m})$.

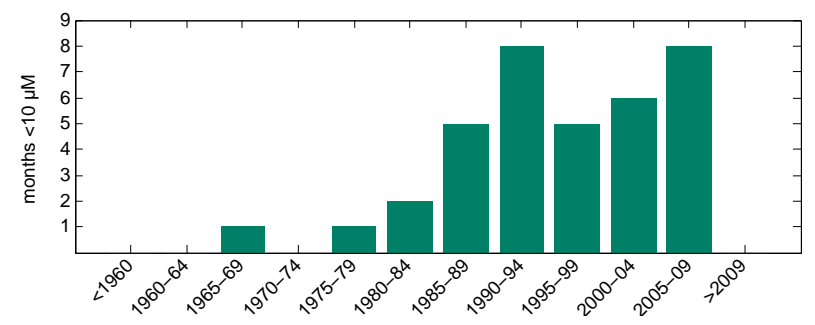

Figure 7. Increasing number of months with oxygen concentrations at $25 \mathrm{~m}$ depth below $10 \mu \mathrm{mol} \mathrm{L}-1$ at BE in 5-year periods. Note that measurements were not continuously available in the periods 1970-1974 and 1980-1984.

winter months December to February, the highest concentrations were present. During the summer months April to July, the mean and the variations between years were smaller by $0.12 \pm 0.15 \mu \mathrm{molL}^{-1}$.

Phosphate was the only series where the standard deviation fluctuated intensively after the gap filling from 1967 to 1979 and 1983 to 1986 . Hence, for the MKT, only the time series starting on 7 January 1986 is used. Testing for monthly trends revealed significant negative trends for the winter months December to March, as well as September (Table 3). The strongest decrease was detected in December, and the weakest in September. To compare the nutrients among each other, the concentrations during the winter months December, January and February were averaged and linear regression was performed, which yielded a linear decrease of $-0.095 \mu \mathrm{molL}^{-1} \mathrm{yr}^{-1}$ for phosphate (Table 5, Fig. 5). Phosphate concentrations in the period after 1986 decreased, but did not yet reach the level of concentrations at the beginning of the 1960s. (Fig. 5)

The phosphate concentration at $25 \mathrm{~m}$ near the sediment varied seasonally, but the seasonal variation differed strongly from the one at $10 \mathrm{~m}$ depth. The yearly maximum at $25 \mathrm{~m}$ depth was in October, not in January as in the $10 \mathrm{~m}$ time series (Fig. 3). Here, the phosphate concentrations were on
Table 3. Test statistics of monthly Mann-Kendall tests part II. Only significant results are shown. Tau $b$ : Kendall coefficient for time series including ties; Sen's slope: median slope present in time series $\left(\mathrm{yr}^{-1}\right)$; C.I.: confidence interval of Sen's slope.

\begin{tabular}{|c|c|c|c|c|c|}
\hline & Tau $b$ & $p$ value & Sen's slope & C.I. $5 \%$ & C.I. $95 \%$ \\
\hline \multicolumn{6}{|c|}{ Nitrate $10 \mathrm{~m}\left(\mu \mathrm{molL}{ }^{-1}\right)$} \\
\hline Jan & -0.33 & 0.017 & -0.17 & -0.29 & -0.02 \\
\hline $\mathrm{Feb}$ & -0.38 & 0.002 & -0.26 & -0.41 & -0.10 \\
\hline Mar & -0.35 & 0.002 & -0.18 & -0.44 & -0.04 \\
\hline Apr & -0.49 & $<0.001$ & -0.05 & -0.08 & -0.03 \\
\hline Jun & -0.33 & 0.017 & -0.01 & -0.02 & 0.00 \\
\hline Aug & -0.31 & 0.008 & -0.01 & -0.01 & 0.00 \\
\hline Oct & -0.37 & 0.008 & -0.01 & -0.02 & 0.00 \\
\hline \multicolumn{6}{|c|}{ Nitrite $10 \mathrm{~m}\left(\mu \mathrm{mol} \mathrm{L}^{-1}\right)$} \\
\hline Jan & -0.29 & 0.050 & -0.02 & -0.03 & 0.00 \\
\hline Mar & -0.26 & 0.027 & -0.02 & -0.03 & 0.00 \\
\hline Apr & -0.28 & 0.024 & 0.00 & 0.00 & 0.00 \\
\hline Oct & -0.36 & 0.014 & 0.00 & -0.01 & 0.00 \\
\hline \multicolumn{6}{|c|}{ Phosphate $10 \mathrm{~m}\left(\mu \mathrm{molL} \mathrm{L}^{-1}\right)$} \\
\hline Jan & -0.37 & 0.013 & -0.02 & -0.03 & 0.00 \\
\hline Mar & -0.34 & 0.005 & -0.02 & -0.04 & 0.00 \\
\hline Apr & -0.26 & 0.038 & 0.00 & -0.01 & 0.00 \\
\hline \multicolumn{6}{|c|}{ Ammonium $10 \mathrm{~m}\left(\mu \mathrm{molL}^{-1}\right)$} \\
\hline Jan & -0.31 & 0.035 & -0.09 & -0.16 & -0.01 \\
\hline Feb & -0.49 & 0.000 & -0.12 & -0.18 & -0.07 \\
\hline Mar & -0.37 & 0.002 & -0.02 & -0.03 & 0.00 \\
\hline Apr & -0.38 & 0.002 & -0.01 & -0.03 & 0.00 \\
\hline Aug & 0.25 & 0.039 & 0.00 & 0.00 & 0.01 \\
\hline \multicolumn{6}{|c|}{ Phosphate $25 \mathrm{~m}\left(\mu \mathrm{molL} \mathrm{L}^{-1}\right)$} \\
\hline Jan & -0.27 & 0.074 & -0.01 & -0.03 & 0.00 \\
\hline Feb & -0.44 & 0.000 & -0.02 & -0.03 & -0.01 \\
\hline Mar & -0.42 & 0.000 & -0.03 & -0.05 & -0.01 \\
\hline Apr & -0.25 & 0.042 & -0.01 & -0.03 & 0.00 \\
\hline Jun & 0.29 & 0.034 & 0.02 & 0.00 & 0.04 \\
\hline Sep & -0.25 & 0.030 & -0.12 & -0.25 & -0.01 \\
\hline
\end{tabular}

average $0.95 \pm 0.72 \mu \mathrm{molL} \mathrm{L}^{-1}$ throughout the year except for the months of September and October. During these months, the concentration was elevated to $3.7 \pm 3.4 \mu \mathrm{mol} \mathrm{L}^{-1}$, which is considerably higher than the maxima at $10 \mathrm{~m}$ depth. The elevated concentration in these months was coincident with the lowest oxygen concentrations during the course of 1 year. Negative trends in phosphate concentrations were present in the winter and spring months January to April (Table 3). A decrease of $-0.1 \mu \mathrm{molL}^{-1}$ per year was present in the September data, which is 1 order of magnitude higher than the other significant trends (3).

\subsubsection{Nitrate}

The seasonal dynamic of the nitrate concentration at $10 \mathrm{~m}$ was similar to the dynamic of phosphate concentration at the same depth. Nitrate concentrations were highest in the winter months December to February, with the maximum in February. Measurements were only continuously available from 1986 on; thus the trends refer only to the period 1986-2013. 
MKT was performed for the months individually as heterogeneous monthly trends were present. Nitrate concentrations decreased significantly between December and April for the period 1986 to 2013. The decrease was strongest in February, with a decrease of $-0.3 \mu \mathrm{molL}^{-1} \mathrm{yr}^{-1}$ (Table 3). For the winter months DJF, linear regression yielded a decrease of $-0.16 \mu \mathrm{molL}^{-1} \mathrm{yr}^{-1}$ (Fig. 5).

\subsubsection{Nitrite}

The nitrite concentration at $10 \mathrm{~m}$ depth showed a similar seasonality as the nutrients described above (Fig. 3). During the summer months April to September, the concentration was on average in the range of $0.05-0.01 \mu \mathrm{molL}^{-1}$ with the highest concentration of that period in June and the lowest in September and October. However, the concentration was on average the highest each year during the winter months January and February.

Nitrite measurements have only been available since 1988, and the trends only refer to this period (1988-2013). No homogeneous trends could be detected for all seasons; hence the months were tested individually for a long-term trend. A significant downward trend was evident in January, March and April (Table 3). The linear regression for the winter months DJF showed a decreasing trend of $-0.0085 \mu \mathrm{molL}^{-1} \mathrm{yr}^{-1}$ (Fig. 5).

\subsubsection{Ammonium}

Ammonium concentration at $10 \mathrm{~m}$ depth displayed a similar seasonal cycle as the other nutrients at the same depth with higher concentrations during the winter months December to February and lower concentrations during summer (Fig. 3). During the summer months, the concentrations were in a mean range of $0.44 \pm 0.45 \mu \mathrm{molL}^{-1}$ (October) to $0.87 \pm 1.73 \mu \mathrm{molL}^{-1}$ (March). For the MKT, only the time series after 1986 were considered, as continuous data before 1986 were sparse. No homogenous trend could be detected for the series including all months, so the months were tested individually. Decreasing trends were present in the months of January to April (Table 3). In August, a significant increasing trend was detected. If a linear trend is assumed for the year to year variation of the winter months DJF, the decrease is $-0.14 \mu \mathrm{mol} \mathrm{L}^{-1} \mathrm{yr}^{-1}$ (Fig. 5).

The ammonium concentration at $25 \mathrm{~m}$ depth displayed a different seasonality. In general, the mean concentration was higher than at $10 \mathrm{~m}$. Furthermore, the seasonal cycle had its yearly maxima on average in May and October, and not during the winter months as at $10 \mathrm{~m}$ depth. Trends were again only evaluated for the period after 1986 and were tested individually as well, as there was no homogenous trend for all seasons present. However, none of the trends were significant.

\subsubsection{Chlorophyll $a$}

The mean yearly distribution of the chlorophyll $a$ concentration in the water column displayed clear seasonal variations (Fig. 3). Throughout the water column, the concentrations were highest in March. In contrast to this spring peak, the maximal values for the second maximum in a year were more diversely distributed among the months August to December, and hence the second maximum could not be dated to a single month. The time series was segmented into two main parts, ranging from 1960 to 1975 (I) and 1988 to 2012 (II). These series differed considerably in mean chlorophyll $a$ concentrations and were therefore analysed separately (Fig. 4). During the first series (I), chlorophyll $a$ concentrations were on average $5.57 \pm 6.39 \mu \mathrm{g} \mathrm{L}^{-1}$. In series II, the average concentration was lower by $2.85 \pm 2.20 \mu \mathrm{g} \mathrm{L}^{-1}$. However, the average seasonality did not change, as the highest mean concentrations in both series were detected in March and during a second maximum in fall. The lowest concentrations per year were most often found in January.

The two parts of the time series were separately tested for trends with the MKT. Chlorophyll $a$ concentrations in series I did show a homogenous tendency, but no significant trend could be detected (Table 2). For series II, concentrations were rising significantly in February with an increase of $0.06 \mu \mathrm{g} \mathrm{L}-1$. Significant negative trends were detected in April, May, July and October (Table 2). In the trends of the extreme values, e.g. the $90 \%$ quantile, a significant trend was detected for series II. The quantile is decreasing by $-0.12 \mu \mathrm{g} \mathrm{L}^{-1} \mathrm{yr}^{-1}$, which is twice as high as the median decrease computed with Sen's slope (Table 4).

\subsubsection{Secchi depth}

Secchi depth displayed fluctuations throughout the whole period from 1986 to 2013 (not shown). The mean Secchi depth was $6.8 \pm 1.8 \mathrm{~m}$, with a mean amplitude of $2.1 \mathrm{~m}$. The shallowest Secchi depth usually occurs in March $(6.1 \mathrm{~m})$, and the deepest in January $(8.2 \mathrm{~m})$. Although a negative median slope was present, it was not significant $(p=0.9)$. However, extremely deep Secchi depths decreased, indicated by the regression of the $90 \%$ quantile, which decreased by $0.08 \mathrm{~m}$ per year (Table 2).

\subsection{Model accuracy at the BE location}

The agreement between model output and observations at the location of Boknis Eck was overall good with respect to the $1: 1$ comparison, the trend and the averages of the parameters temperature, salinity and oxygen, although minor discrepancies remain. Observed temperature agreed best with model output, especially at the surface $\left(R^{2}=0.98\right.$, Fig. 8$)$. The linear trend in the period 1970-2010 was captured very well when only the days with measurements at $\mathrm{BE}$ were considered (Table 6), which resulted in a difference of $0.1^{\circ} \mathrm{C}$ per 
Table 4. Descriptive and test statistics for Mann-Kendall test (MKT) and quantile regression. SD: standard deviation; filled: time series after gap filling described in Sect. 2.2; Tau $b$ : Kendall coefficient for time series including ties; Sen's slope: median slope present in time series $\left(\mathrm{yr}^{-1}\right)$; p.t.: pooled trends with bootstrapping of 500 generated time series described in Sect. 2.2. * denotes significance on the 0.1 level for quantile regression.

\begin{tabular}{|c|c|c|c|c|c|c|}
\hline & $\begin{array}{r}\text { Temperature } \\
{ }^{\circ} \mathrm{C}\end{array}$ & $\begin{array}{r}\text { Temperature } \\
{ }^{\circ} \mathrm{C}\end{array}$ & $\begin{array}{r}\text { Salinity } \\
\text { psu }\end{array}$ & $\begin{array}{r}\text { Oxygen } \\
\mu \mathrm{M}\end{array}$ & $\begin{array}{r}\text { Chlorophyll } a \mathrm{I} \\
\mu \mathrm{g} \mathrm{L}^{-1}\end{array}$ & $\begin{array}{r}\text { Chlorophyll } a \text { II } \\
\mu \mathrm{gL}^{-1}\end{array}$ \\
\hline Depth & $1 \mathrm{~m}$ & $25 \mathrm{~m}$ & $25 \mathrm{~m}$ & $25 \mathrm{~m}$ & $10 \mathrm{~m}$ & $10 \mathrm{~m}$ \\
\hline Start date & 30 Apr 1957 & 30 Apr 1957 & 30 Apr 1957 & 30 Apr 1957 & 31 Mar 1960 & 19 Apr 1988 \\
\hline End date & 6 Feb 2013 & 6 Feb 2013 & 6 Feb 2013 & 6 Feb 2013 & 2 Dec 1975 & 26 Jun 2012 \\
\hline Mean & 9.74 & 7.02 & 21.55 & 183.52 & 5.47 & 2.86 \\
\hline $\mathrm{SD}$ & 6.00 & 3.64 & 2.35 & 116.95 & 6.39 & 2.06 \\
\hline Missing values [\%] & 17.91 & 18.69 & 19.22 & 19.35 & 5.05 & 15.28 \\
\hline Mean filled & 9.57 & 7.00 & 21.53 & 186.59 & 5.46 & 2.68 \\
\hline SD filled & 5.90 & 3.37 & 2.17 & 112.77 & 6.31 & 2.10 \\
\hline \multicolumn{7}{|c|}{ Mann-Kendall Test } \\
\hline homogeneity & no & yes & yes & no & yes & no \\
\hline Tau $b$ seasonal & 0.15 & 0.19 & 0.01 & -0.22 & 0.11 & -0.16 \\
\hline$p$ value & $<0.001$ & 0.273 & 0.943 & 0.238 & 0.408 & 0.470 \\
\hline Sen's slope & 0.02 & 0.02 & 0.002 & -0.91 & 0.07 & -0.04 \\
\hline \multicolumn{7}{|c|}{ Quantile regression } \\
\hline $90 \%$ quantile data & 0.002 & n.d. & -0.001 & -0.052 & $-0.011 *$ & $-0.007 *$ \\
\hline p.t. $95 \%$ & 0.003 & n.d. & 0.002 & 0.064 & 0.008 & 0.004 \\
\hline p.t. $5 \%$ & -0.003 & n.d. & -0.002 & -0.063 & -0.008 & -0.004 \\
\hline $10 \%$ quantile data & 0.001 & n.d. & $0.002 *$ & $-0.066^{*}$ & -0.001 & -0.002 \\
\hline p.t. $95 \%$ & 0.003 & n.d. & 0.002 & 0.051 & 0.043 & 0.016 \\
\hline p.t. $5 \%$ & -0.003 & n.d. & -0.002 & -0.052 & -0.040 & -0.018 \\
\hline
\end{tabular}
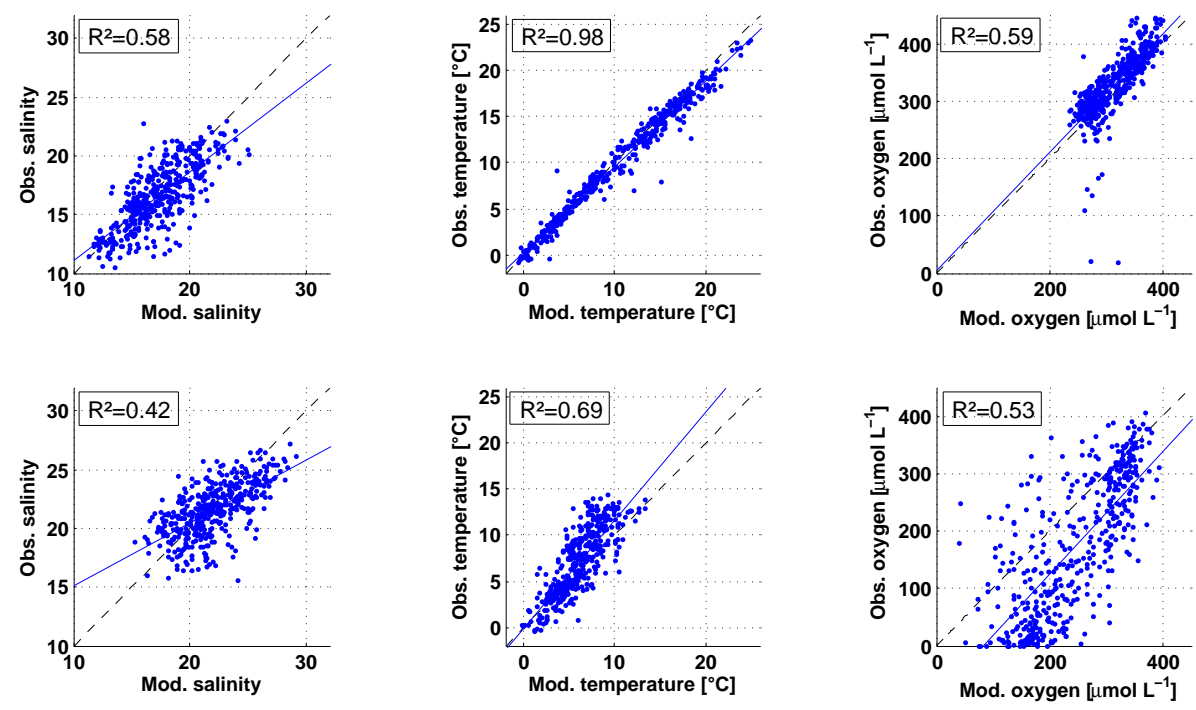

Figure 8. Linear regression of model output (BSIOM at location of BE) vs. observations (BE time series) for salinity, temperature and oxygen concentration. The top row shows the surface, and the bottom one the bottom layer comparison. Note that in the model the bottom layer is $21-24 \mathrm{~m}$ while it is $25 \mathrm{~m}$ in the observations. Obs.: observation; Mod.: model output.

decade. However, it differed from the trend when all the days were considered by $0.3^{\circ} \mathrm{C}$ per decade. Also, the mean observed and modelled temperature agreed very well in both the surface and bottom layer. In the bottom layer, the trends were identical regardless of which temporal resolution was considered for trend calculation. This is not surprising because the temperature evolution is tied to the atmospheric forcing, i.e. boundary conditions. Modelled salinity agreed 
less accurately than temperature with the observations. The salinity evolution is coupled to the overall water budget, including the net freshwater flux and the western boundary condition for salinity, which are much more uncertain. The trends in model and observations showed different directions but were both nonsignificant and very small compared to the general salinity of approximately 22 (Table 6). Furthermore, the model overestimated oxygen concentrations in the bottom layer substantially; the surface layer concentrations, however, were met except for periods where extremely low oxygen conditions prevailed (Fig. 8). However, the trends of $-1.14 \mu \mathrm{mol} \mathrm{L}^{-1} \mathrm{yr}^{-1}$ in the observations as well as -1.32 (modelled) and $-1.47 \mu \mathrm{molL}^{-1} \mathrm{yr}^{-1}$ (modelled at day of BE observations) were only slightly overestimated in the model (Table 6).

Model output was used to investigate the thermal stratification and the oxygen consumption rate with a daily instead of monthly resolution. The time during which the water column at BE was stable stratified was difficult to determine, as the duration of stratification highly depended on the temperature gradient criterion assumed. Temperature gradients between 0.6 and $1.4^{\circ} \mathrm{Cm}^{-1}$ were tested and yielded different results (Table 7). However, the duration of stratification was increasing ( 1 to $10.25 \mathrm{ddecade}^{-1}$ ) and the onset of stratification started earlier ( 2.75 to $8.25 \mathrm{~d} \mathrm{decade}^{-1}$ ) for all criteria tested.

The effect of the rising temperature trend on oxygen consumption rates was relatively small. Only $13 \%$ $\left(0.2 \mu \mathrm{molL}^{-1} \mathrm{yr}^{-1}\right)$ of the total oxygen decrease of $-1.47 \mu \mathrm{molL}^{-1} \mathrm{yr}^{-1}$ could be attributed to an enhancement of the oxygen consumption by temperature in the model. The remaining part originated from the prescribed primary production, to which the oxygen consumption rate was tied (see Sect. 2.3).

\section{Discussion}

\subsection{Comparisons of observations at BE with trends in the Baltic Sea}

Statistical analysis of the time series at BE revealed that significant trends were present in all of the nine analysed parameters. The trends comprise physical, chemical and biological parameters and indicate that the whole system undergoes significant changes, resulting, for example, in altered living conditions for biota.

Temperature trends at $\mathrm{BE}$ were in good agreement with trends in other regions of the Baltic Sea. The positive tendency of $0.2^{\circ} \mathrm{C}$ per decade is within the range of previously reported trends (Feistel et al., 2008, ch. 9.4, p. 252ff). The same magnitudes of mean and extreme value warming tendency indicated a general shift towards warmer temperatures, which intensified in the period 1970-2010. Most of the warming in the sea surface at BE can be attributed to the spring season, as April and May were the months with the highest temperature increase. At the same time, temperature in the bottom water did not increase as fast as at the surface, which resulted in an overall significant increase in the density gradient in spring. Hence, stratification starts earlier in a year, which may in turn lead to a reduced ventilation. This is discussed in context with oxygen depletion below.

No significant trend could be detected for salinity at BE in the median, which is in agreement with findings of the BACC author team (BACC, 2008). They report no significant changes in salinity in the 20th century at numerous monitoring stations (BACC, 2008). Salinity fluctuates in the shortterm, interannual variability due to large-scale advection (Lehmann et al., 2013). Major saltwater inflows triggered mainly by westerly wind regimes bring saline water from the North Sea further into the Baltic Sea (Lass and Matthäus, 1996). The strongest inflow occurred in January 1993, less strong events in 1965, 1969, 1973, 1976, 1980 and 2003 (in decreasing magnitude) (BACC, 2008; Feistel et al., 2008, ch. 10 , p. 265ff). The salinity time series at BE does not show pronounced maximal salinities for these dates. It is unlikely that the major salinity inflows did not reach BE, as the time series station is located at the Boknis Eck channel with a direct connection to the Belt Sea. More likely, the bottom water is not suited to track major saltwater inflows as it already reflects the characteristics of the incoming North Sea water. Apparently, an intrusion of saltwater is more pronounced in the horizontal dimension than in the vertical and is hard to detect in a 1-D profile at Boknis Eck.

The nutrient and phytoplankton cycle, the latter indicated by the chlorophyll $a$ concentrations at the surface, showed a typical annual seasonality. Smetacek (1984) described the annual cycle of plankton and nutrients in the Kiel Bight in several stages, which could be observed throughout the whole time span. They comprise a spring bloom, at BE indicated by high chlorophyll $a$ concentrations in March; a herbivorous copepod maximum that could not be detected by the parameters discussed here; a third stage during summer stratification, which was identified here by low nutrient concentration and comparably high chlorophyll $a$ concentrations; and an autumn bloom that varied in timing, again indicated by elevated chlorophyll $a$ concentrations. Smetacek (1984) observed constant nutrient concentrations in winter and consequently a similar bloom size each year during a 10 -year period, which contrasted with the decreasing nutrient concentrations and decreasing chlorophyll $a$ concentrations found over the longer period 1960/1986-2013.

The peak in bottom water ammonium appeared consistently with a lag of 1 month after increased chlorophyll $a$ concentration in the surface layer and was especially strong when anoxic conditions were present. This behaviour may indicate remineralisation of organic matter after the blooms. The lag of 1 month after the dieback of algal blooms was in agreement with previous studies showing an increase in methane 1 month after an algal bloom in the bottom water 
Table 5. Descriptive and test statistics for seasonal (MKT) and linear regression of winter (DJF mean) concentrations. Percentage of missing values in brackets refers to the part of the time series used for statistic analysis. SD: standard deviation; DJF: December-January-February.

\begin{tabular}{|c|c|c|c|c|c|c|}
\hline & $\begin{array}{r}\text { Phosphate } \\
\mu \mathrm{M}\end{array}$ & $\begin{array}{r}\text { Phosphate } \\
\mu \mathrm{M}\end{array}$ & $\begin{array}{r}\text { Nitrate } \\
\mu \mathrm{M}\end{array}$ & $\begin{array}{r}\text { Nitrite } \\
\mu \mathrm{M}\end{array}$ & $\begin{array}{r}\text { Ammonium } \\
\mu \mathrm{M}\end{array}$ & $\begin{array}{r}\text { Ammonium } \\
\mu \mathrm{M}\end{array}$ \\
\hline Depth & $10 \mathrm{~m}$ & $25 \mathrm{~m}$ & $10 \mathrm{~m}$ & $10 \mathrm{~m}$ & $10 \mathrm{~m}$ & $25 \mathrm{~m}$ \\
\hline Start date & 30 Apr 1957 & 30 Apr 1957 & 12 Mar 1979 & 7 Jan 1986 & 12 Mar 1979 & $12 \operatorname{Mar} 1979$ \\
\hline End date & 6 Feb 2013 & 6 Feb 2013 & 6 Feb 2013 & 6 Feb 2013 & 6 Feb 2013 & 6 Feb 2013 \\
\hline Mean & 0.39 & 1.85 & 2.10 & 0.20 & 0.80 & 4.84 \\
\hline SD & 0.42 & 3.40 & 3.43 & 0.27 & 1.48 & 5.15 \\
\hline Missing values [\%] & $\begin{array}{r}32.8 \\
(7.5)\end{array}$ & 34.3 & $\begin{array}{r}48.1 \\
(18.6)\end{array}$ & 7.7 & 9.7 & 11.0 \\
\hline Mean filled & 0.46 & 1.55 & 2.13 & 0.21 & 0.95 & 4.97 \\
\hline $\begin{array}{l}\text { SD filled } \\
\text { Linear regression (D. }\end{array}$ & 0.45 & 1.72 & 3.20 & 0.27 & 1.43 & 5.10 \\
\hline $\begin{array}{l}\text { slope } \mathrm{yr}^{-1} \\
\text { Pearson's } R\end{array}$ & $\begin{array}{l}-0.24 \\
-0.72\end{array}$ & $\begin{array}{l}-0.22 \\
-0.61\end{array}$ & $\begin{array}{l}-1.54 \\
-0.54\end{array}$ & $\begin{array}{l}-0.07 \\
-0.37\end{array}$ & $\begin{array}{l}-1.12 \\
-0.59\end{array}$ & $\begin{array}{l}-0.73 \\
-0.32\end{array}$ \\
\hline
\end{tabular}

Table 6. Comparison of linear trends in observed and modelled parameters temperature (surface and bottom layer), salinity and oxygen concentration (bottom layer). To ensure comparability, trends only relate to the period 1970-2010, limited by the model output. Note that the bottom layer is at a depth of $25 \mathrm{~m}$ in the observations but $21-24 \mathrm{~m}$ in the model. O: observations; M: BSIOM output; M./O.: model output only on days with BE observations.

\begin{tabular}{|c|c|c|c|c|}
\hline & $\begin{array}{r}\text { Temperature } \\
\text { surface } \\
{ }^{\circ} \mathrm{C}\end{array}$ & $\begin{array}{r}\text { Temperature } \\
\text { bottom } \\
{ }^{\circ} \mathrm{C}\end{array}$ & $\begin{array}{r}\text { Salinity } \\
\text { bottom } \\
-\end{array}$ & $\begin{array}{r}\text { Oxygen } \\
\text { bottom } \\
\mu_{\text {mol L }}{ }^{-1}\end{array}$ \\
\hline Trend O. $\mathrm{yr}^{-1}$ & +0.07 & +0.03 & +0.04 & -1.14 \\
\hline Trend M. $\mathrm{yr}^{-1}$ & +0.04 & +0.03 & -0.04 & -1.32 \\
\hline Trend M./O. $\mathrm{yr}^{-1}$ & +0.06 & +0.03 & -0.03 & -1.47 \\
\hline Mean \pm SD O. & $9.87 \pm 6.0$ & $7.14 \pm 3.4$ & $21.57 \pm 2.3$ & $74.15 \pm 117.0$ \\
\hline Mean \pm SD M. & $9.97 \pm 6.3$ & $5.91 \pm 2.5$ & $22.04 \pm 2.7$ & $252.34 \pm 79.8$ \\
\hline
\end{tabular}

found by Bange et al. (2010), which they also attributed to remineralisation. Ammonium accumulation is known to occur during the decomposition of organic matter, when further oxidation to nitrite and nitrate is hindered by low oxygen concentrations.

Although the seasonal cycle varied only little with respect to the yearly course, the magnitude of the nutrient and chlorophyll $a$ concentration did change significantly during 1980-2013 (nutrients) and 1960-2013 (chlorophyll a). In general, the concentrations of nutrients during the winter months were significantly decreasing. This decrease has been detected in several other stations of the Baltic Sea as well. For nitrate, trends in the Bornholm and Gotland basins increased until the early 1990s and decreased thereafter (Feistel et al., 2008 , ch. 12.2 , p. 344f). Conley et al. (2002) analysed total nitrogen concentrations in the Danish waters and found a decrease from 1980 to 2003. Carstensen et al. (2006) reported a decrease of the nutrient discharges from Denmark by $50 \%$ from 1988 to 2002. In the BE time series, nitrate measurements were only available from 1986 on, but the general decrease since then was confirmed. For phosphorous discharge, Carstensen et al. (2006) detected a decrease of $80 \%$, which they attributed mainly to the installation of wastewater treatment plants. Further studies found phosphate to increase un- til the 1980s, with strong fluctuations without a clear trend thereafter (Feistel et al., 2008, ch. 12.3, p. 345). Phosphate did show stronger fluctuations than nitrate in the BE series, but the decreasing tendency was significant in the winter months.

Accompanied by this significant decrease in nutrient concentrations is a decline in chlorophyll $a$ concentrations. This is most striking when comparing the means between the two chlorophyll series 1960-1975 and 1986-2013, where the concentration fell from $5.5 \pm 6.39$ to $2.9 \pm 2.6 \mu \mathrm{g} \mathrm{L}^{-1}$. Additionally, decreasing trends for the second period were found. As lower nutrients concentrations would lead to less production and less intense algal blooms, these findings match well. HELCOM (2009) registered a decreasing trend in chlorophyll $a$ concentrations since the mid-1990s for the Kattegat and Belt Sea, with an increasing tendency from 2000 on. Wasmund and Uhlig (2003) also found a decreasing, yet nonsignificant, trend for the chlorophyll $a$ concentrations in the Kattegat and Belt Sea and attributed it to the decreasing nutrient concentrations. In general, chlorophyll $a$ trends in the regions of the Danish straits are highly variable, and even opposite trends can be found for individual regions (HELCOM, 2009). Due to phytoplankton blooms lasting shorter than the sampling interval, trends in chlorophyll $a$ are sensitive to the 
Table 7. Trends (1970-2010) and length of stratification period in the BSIOM output depending on different temperature criteria used to detect stable stratification. Temp.: temperature; strat.: stratification; doy: day of year; d: days; dec.: decade.

\begin{tabular}{rrrrrrr}
\hline $\begin{array}{r}\text { Temp. } \\
\text { criterion } \\
{ }^{\circ} \mathrm{C} \mathrm{m}^{-1}\end{array}$ & $\begin{array}{r}\text { Begin } \\
\text { strat. } \\
\text { doy }\end{array}$ & $\begin{array}{r}\text { End } \\
\text { strat. } \\
\text { doy }\end{array}$ & $\begin{array}{r}\text { Mean } \\
\text { duration } \\
\text { d }\end{array}$ & $\begin{array}{r}\text { Trend onset } \\
\text { strat. } \\
\text { ddec. }^{-1}\end{array}$ & $\begin{array}{r}\text { Trend end } \\
\text { strat. } \\
\text { ddec. }^{-1}\end{array}$ & $\begin{array}{r}\text { Trend } \\
\text { duration } \\
\text { ddec. }^{-1}\end{array}$ \\
\hline 0.6 & 97.9 & 316.6 & 216 & -6.0 & 2.0 & 8.0 \\
0.8 & 108.1 & 309.1 & 201 & -8.3 & 2.0 & 10.3 \\
1.0 & 121.1 & 301.9 & 181 & -2.8 & -0.8 & 1.8 \\
1.2 & 129.6 & 296.1 & 166 & -3.0 & -1.0 & 2.0 \\
1.4 & 136.1 & 293.3 & 157 & -3.8 & 0.3 & 4.3 \\
\hline
\end{tabular}

sampling date, as the peaks could have been missed. However, the general decreasing trend throughout the whole period of 56 years is still evident.

The annual cycle of Secchi depth with a minimum in March and a maximum during winter matched the findings of the chlorophyll $a$ cycle. The slight decrease in Secchi depth by about $8 \mathrm{~cm} \mathrm{yr}^{-1}$ in the $90 \%$ quantile fits in magnitude with a trend published for the Swedish Baltic Sea by $8 \mathrm{~cm} \mathrm{yr}^{-1}$ (Sanden and Hakansson, 1996), both indicating an increased turbidity.

The oxygen concentration declined significantly with a simultaneous increase in hypoxic and anoxic events in the bottom water during the period 1957-2013 at BE. The spreading of hypoxic and even anoxic zones in marine coastal ecosystems is known to occur worldwide and is often related to eutrophication (Diaz and Rosenberg, 2008). The Baltic Sea is affected by oxygen decline over large areas (HELCOM, 2009), which have expanded since 2001. The temporal extension of hypoxia matches well with the oxygen decline at BE.

\subsection{Comparison of observations at BE with BSIOM output}

The BSIOM reproduced observed temperature, salinity and oxygen at the location of BE with an acceptable range of uncertainty. For temperature, it became obvious that the timing of the monthly observation is important for the magnitude of trend, and trends could differ by around $30 \%$ compared to the observed trend. The timing is especially important when parameter variation is high, e.g. for the surface temperature. Observed temperature at the bottom showed only small variations, and trends did not depend strongly on the temporal resolution. In general, the model reproduced the measurements accurately and can therefore be applied in order to look in detail at the development of temperature stratification discussed with oxygen depletion below.

Salinity was reproduced less precisely than temperature (lower correlation, magnitude of trend), but as changes in the ventilation system seem to be driven by temperature changes (see below), salinity was not further considered for finding reasons for the ongoing oxygen decline by model output analysis.

Oxygen trends were similar, despite the simplified oxygen parametrisation in the model. Although concentrations were overestimated, the trend in oxygen depletion is captured well by the model. However, it needs to be noted that only a small fraction of the decreasing oxygen concentration trend can be attributed to a temperature-enhanced oxygen consumption. Most of the oxygen depletion in the model is based on an increase in primary production. Although an increase in primary production is questionable at BE due to significantly decreasing nutrient concentrations, it cannot be excluded, as no direct measurements are available. In general, the oxygen consumption rate is captured well by the model and reflects the trend observed at BE well, but the reasons for that cannot completely be confirmed.

\subsection{Possible reasons for ongoing observed oxygen decline in the bottom water}

\subsubsection{Observations}

First, possible processes causing oxygen depletion in the bottom water are discussed here based on the time series of observations at Boknis Eck. Processes discussed include nutrient remobilisation, the physical process of decreasing solubility of gases with increasing temperature, lower oxygen supply by altered ventilation and temperature-enhanced oxygen consumption rate.

Nutrient remobilisation from the sediment due to lower oxygen concentrations in the bottom water are often cited to contribute to ongoing oxygen decline (see e.g. Conley et al., 2002; Pitkänen et al., 2001). At BE, for example phosphate concentrations in the bottom water were elevated during periods of anoxia, but the general trend was significantly decreasing between 1980 and 2013. If higher concentrations of phosphate due to remobilisation and a subsequently higher production with higher sedimentation of organic matter comprised the only process responsible for the oxygen decline, oxygen concentrations would have increased when phosphate remobilisation decreased. This was not the case, and 


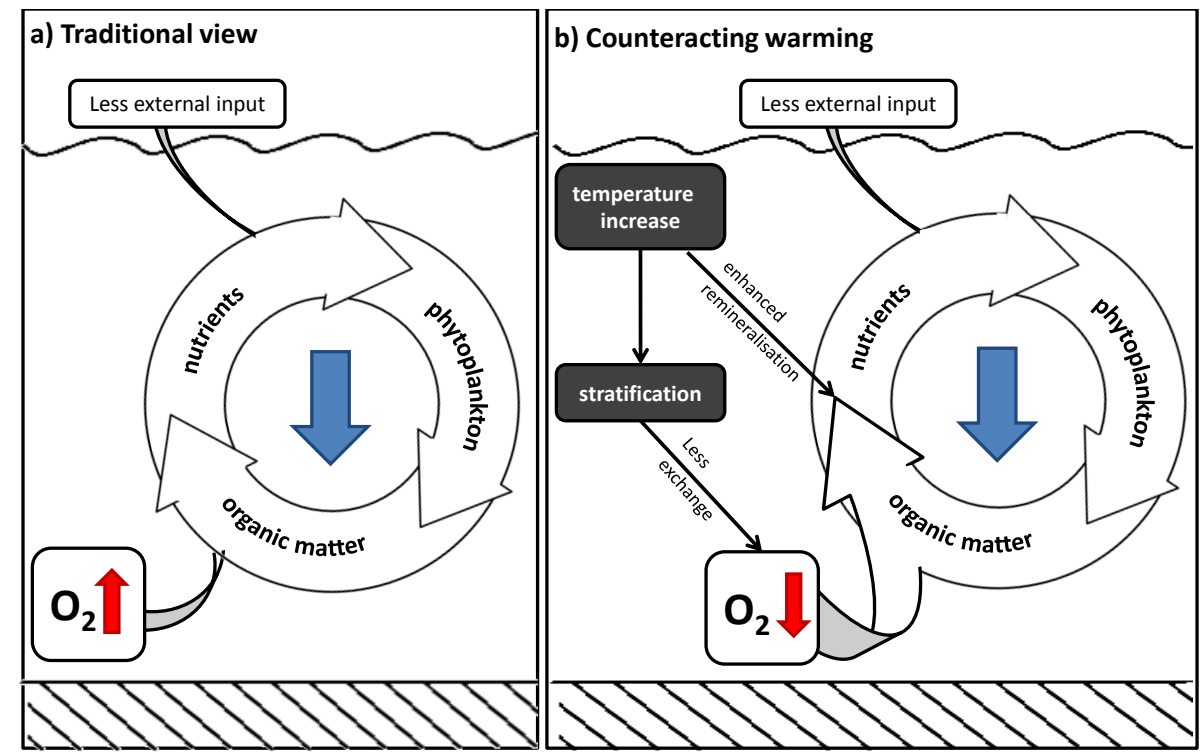

Figure 9. Schematic overview of possible causes for ongoing oxygen decline. (a) The traditional view of declining eutrophication: decreasing nutrient input, less phytoplankton and less organic matter (blue downward arrow) leading to less oxygen consumption and thus rising oxygen concentration (red upward arrow). (b) Alteration by warming temperature (dark grey): on the one hand, rising temperature enhances remineralisation and thus increases oxygen consumption; on the other hand, it increases stratification stability and hampers oxygen supply from surface waters. As a result, oxygen concentration decreases (red downward arrow).

thus phosphate remobilisation may not be the key process responsible for oxygen decline.

Increasing temperature also decreases the solubility of oxygen. However, the oxygen saturations showed a significant decrease as well. In contrast to oxygen concentration, the oxygen saturation already takes into account changes in temperature. A decrease in the oxygen saturation means that the decrease in concentration cannot be attributed completely to the physical effect of solubility.

Rising temperatures further enhance remineralisation of organic matter that is deposited on the bottom, resulting in increased oxygen consumption (Hoppe et al., 2013). This hypothesis is further supported by the lacking trend of bottom water ammonium concentration. Despite lower nutrient input, ammonium concentrations in the bottom water did not decline, indicating that remineralisation might be enhanced by other factors and counterbalance the decrease in nutrients. Rising temperatures might be a possible explanation for this ongoing remineralisation.

Moreover, there is evidence for an alteration in the ventilation at Boknis Eck. At BE, the density gradient across the pycnocline strengthened significantly in the period 1957-2013, especially in spring, when the rise in temperature was greater at the surface than at the bottom. A stronger stratification earlier in the year hampers ventilation and therefore oxygen supply to the bottom water layer and might be a possible reason for intensified oxygen decline. A schematic overview of possible reasons for the ongoing oxygen decline despite decreasing eutrophication is given in Fig. 9.
Whether advection of oxygen-enriched or depleted water through the Danish Straits is a possible reason for the ongoing oxygen decline at BE cannot be estimated accurately on the basis of a one-dimensional time series such as BE. After the main inflowing events (see Sect. 4.1), no major change could be seen in the bottom water oxygen concentrations at BE. In summary, observations indicate that the ongoing oxygen depletion might be caused by an altered ventilation, including an earlier onset of stable stratification, as well as enhanced oxygen consumption, possibly triggered by rising temperatures in the bottom water at BE.

\subsubsection{Model output}

The daily model output indicated a prolongation of the stratification period at $\mathrm{BE}$, although the length of the stratification strongly depends on the temperature difference criteria chosen to detect the thermocline. All of the chosen criteria between 0.6 and $1.4{ }^{\circ} \mathrm{Cm}^{-1}$ led to a prolongation and an earlier onset of stable stratification.

The second possible reason was oxygen decline due to enhanced remineralisation rates. In the BSIOM, oxygen consumption is only based on temperature-dependent consumption rate, which is related to prescribed primary production (see Sect. 2.3). Although this parametrisation is a strong simplification and is based on the only available but sparse data set of primary production (Wasmund et al., 2011), the trends of oxygen concentration were very well captured. The reasons for the increase in oxygen consumption in the model are 
based on an increase in primary production, which is debatable at the location of BE. The fact that nutrient concentrations are significantly decreasing points against an increase in primary production when they are considered at the same time as the limiting factor (Wasmund et al., 2011). However, as direct measurements are not available at BE, it cannot be excluded that increasing primary production is the reason for the ongoing oxygen decline. In summary, the magnitude of the oxygen consumption rate seems to be accurate in the model, but the reasons for the ongoing oxygen decline cannot be completely resolved based on the BSIOM output, as the basic assumption of increasing primary production can be neither confirmed nor rejected.

\section{Conclusions}

The detection of significant long-term trends in all of the studied oceanographic parameters in the period of 1957 to 2013 revealed that Boknis Eck is subjected to extensive changes that comprise biological, biogeochemical and physical factors, with implications for the ecosystem. The observed trends for increasing temperature and decreasing oxygen concentration in the bottom water are representative of the southwestern Baltic Sea; decreasing chlorophyll $a$ and nutrient concentration were in the range of observations elsewhere, although these parameters have very variable spatial patterns in the Baltic Sea. In general, monitoring at the Boknis Eck time series station is valuable for detecting changes that reflect variations in large parts of the southwestern Baltic Sea.

Oxygen concentration in the bottom water at BE decreased significantly despite the decrease in nutrient concentrations. Based on the observed temporal development of the physical and biological parameters at BE, we hypothesise that enhanced remineralisation due to temperature increase and a longer lasting stratification may enhance oxygen depletion. It could be proved that the remobilisation of phosphate from anoxic sediments might act as a long-term nutrient source. However, the remobilisation is unlikely to significantly enhance oxygen consumption through organic matter mineralisation by triggering phytoplankton growth, as the general trend was decreasing.

The comparison to the temporarily higher resolved model output revealed that the period of stratification had an prolonging effect, although the magnitude of the prolongation depends on the temperature criteria chosen to identify the stratification. Oxygen depletion trends were captured well by the model, but the reasons for increased oxygen consumption were only ca. $13 \%$ attributable to the temperature increase. The remaining part may be attributed to an increase in primary production implemented in the BSIOM. Furthermore, it could be shown that the monthly temporal resolution of $\mathrm{BE}$ observations may lead to inaccuracies in the trends, especially when the parameter shows high short-term fluctu- ations. Continuing the monthly measurements at the Boknis Eck time series station is of major importance for monitoring and understanding future changes in the southwestern Baltic Sea. An extension of the parameters including in situ primary production would be helpful in verifying the hypothesis of increasing primary production despite a decrease in nutrients as a reason for the ongoing oxygen decline.

Acknowledgements. The authors thank the captain and crew of the RV Littorina and Polarfuchs as well as the many colleagues and numerous students who helped to continue the BE time series through various projects. We thank Christian Franzke for generously providing his MatLab scripts. The time series BE was supported by DWK Meeresforschung (1957-1975), HELCOM (1979-1995), BMBF (1995-1999), the Institut für Meereskunde (1999-2003), IfM-GEOMAR (2004-2011) and GEOMAR (2012-present). $\mathrm{BE}$ is a LOICZ affiliated project. The Boknis Eck time series station (www.bokniseck.de) is run by the Chemical Oceanography Research Unit of GEOMAR, Helmholtz Centre for Ocean Research Kiel. We thank Viktor Smetacek and the anonymous referee for helpful comments that helped in improving the manuscript.

The service charges for this open access publication have been covered by a Research Centre of the Helmholtz Association.

Edited by: T. Treude

\section{References}

Babenerd, B.: Increasing oxygen deficiency in Kiel Bay (Western Baltic) - a paradigm of progressing coastal eutrophication, Meeresforschung, 30, 121-140, 1991.

BACC: Assessment of Climate Change for the Baltic Sea Basin, Springer, 2008.

Bange, H. W., Bergmann, K., Hansen, H. P., Kock, A., Koppe, R., Malien, F., and Ostrau, C.: Dissolved methane during hypoxic events at the Boknis Eck time series station (Eckernförde Bay, SW Baltic Sea), Biogeosciences, 7, 1279-1284, doi:10.5194/bg7-1279-2010, 2010.

Bange, H. W., Hansen, H.-P., Malien, F., Lass, K., Dale, A., Karstensen, J., Petereit, C., and Friedrichs, G.: Boknis Eck Time Series Station (SW Baltic Sea): Measurements from 1957 to 2010, LOICZ-Affiliated Activities, 2011.

Bendtsen, J. and Hansen, J. L. S.: Effects of global warming on hypoxia in the Baltic Sea-North Sea transition zone, Ecol. Model., 264, 17-26, 2013.

Bumke, K., Karger, U., Hasse, L., and Niekamp, K.: Evaporation over the Baltic Sea as an example of a semi-enclosed sea, Contr. Atmos. Phy., 71, 249-261, 1998.

Burkey, J.: Matlab Function: Seasonal Kendall Trend Test for Data with and without Serial Dependance, MatLab fileexchange, 2012.

Carstensen, J., Conley, D. J., Andersen, J. H., and Aertebjerg, G.: Coastal eutrophication and trend reversal: a Danish case study, Limnol. Oceanogr., 5, 398-408, 2006. 
Conley, D. J., Humborg, C., Rahm, L., Savchuk, O. P., and Wulff, F.: Hypoxia in the Baltic Sea and basin-scale changes in phosphorus biogeochemistry, Env. Sci. Tech., 36, 5315-5320, 2002.

Ducklow, H. W., Doney, S. C., and Steinberg, D. K.: Contributions of long-term research and time-series observations to marine ecology and biogeochemistry, Annu. Rev. Mar. Sci., 1, 279-302, 2009.

Diaz, R. and Rosenberg, R.: Spreading dead zones and consequences for marine ecosystems, Science, 321, 926-930, 2008.

Feistel, R., Nausch, G., and Wasmund, N.: State and Evolution of the Baltic Sea, 1952-2005: a Detailed 50-Year Survey of Meteorology and Climate, Physics, Chemistry, Biology and Marine Environment, Wiley-Blackwell (an imprint of John Wiley \& Sons Ltd), 2008.

Franzke, C.: A novel method to test for significant trends in extreme values in serially dependent time series, Geophys. Res. Lett., 40, 1391-1395, 2013.

Garcia, H. E. and Gordon, L. I.: Oxygen solubility in seawater: better fitting equations, Limnol. Oceanogr., 37, 1307-1312, 1992.

Grasshoff, K., Kremling, K., and Ehrhardt, M.: Methods of Seawater Analysis, Wiley-VCH, 3rd Edn., 1999.

Hanninen, J., Vuorinen, I., and Hjelt, P.: Climatic factors in the Atlantic control the oceanographic and ecological changes in the Baltic Sea, Limnol. Oceanogr., 45, 703-710, 2000.

Hansen, H. P., Giesenhagen, H. C., and Behrends, G.: Seasonal and long-term control of bottom-water oxygen deficiency in a stratified shallow-water coastal system, ICES J. Mar. Sci., 56, 65-71, 1999.

Hansen, J. L. S. and Bendtsen, J.: Effects of climate change on hypoxia in the North Sea - Baltic transition zone, IOPC Ser. Earth Environ. Sci., 6, Copenhagen, Denmark, 2009.

HELCOM: Convention on the protection of the marine environment of the Baltic Sea area, Helsinki Convention, 1-27, 1974.

HELCOM: Eutrophication in the Baltic Sea - an integrated assessment of the effects of nutrient enrichment in the Baltic Sea region, Baltic Sea Environ. Proc., 115, 1-145, 2009.

Hirsch, R. M. and Slack, J. R.: A nonparametric trend test for seasonal data with serial dependence, Water Resour. Res., 20, 727-732, 1984.

Hoppe, H.-G., Giesenhagen, H. C., Koppe, R., Hansen, H.-P., and Gocke, K.: Impact of change in climate and policy from 1988 to 2007 on environmental and microbial variables at the time series station Boknis Eck, Baltic Sea, Biogeosciences, 10, 4529-4546, doi:10.5194/bg-10-4529-2013, 2013.

Jonasson, L., Hansen, J. L. S., Wan, Z., and She, J.: The impacts of physical processes on oxygen variations in the North Sea-Baltic Sea transition zone, Ocean Sci., 8, 37-48, doi:10.5194/os-8-372012, 2012.

Koenker, R. and Hallock, K.: Quantile regression, Jour. Econ. Persp., 15, 143-156, 2001.

Krey, J.: Die Bestimmung des Chlorophyll a in MeerwasserSchöpfproben, Meereskundliche Arbeiten der Univeristät zu Kiel, 65, 201-209, 1939.

Krey, J., Babenerd, B., and Lenz, J.: Beobachtungen zur Produktionsbiologie des Planktons in der Kieler Bucht 1957-1975, Berichte aus dem Institut für Meereskunde, 1, 1-20, 1980.

Kronsell, J. and Andersson, P.: Total regional runoff to the Baltic Sea, HELCOM Baltic Sea Environment Fact Sheets 2012, available at: http://helcom.fi/ baltic-sea-trends/environment-fact-sheets/hydrography/ total-and-regional-runoff-to-the-baltic-sea/, 2012.

Lass, H. U. and Matthäus, W.: On temporal wind variations forcing salt water inflows into the Baltic Sea, Tellus A, 48, 663-671, 1996.

Lehmann, A.: A three-dimensional baroclinic eddy-resolving model of the Baltic Sea, Tellus A, 47, 1013-1031, 1995.

Lehmann, A. and Hinrichsen, H.-H.: On the thermohaline variability of the Baltic Sea, J. Mar. Syst., 25, 333-357, 2000.

Lehmann, A., Krauss, W., and Hinrichsen, H.-H.: Effects of remote and local atmospheric forcing on circulation and upwelling in the Baltic Sea, Tellus A, 54, 299-316, 2002.

Lehmann, A., Myrberg, K., and Getzlaff, K.: Salinity dynamics of the Baltic Sea, Baltic Earth newsletter, 1, 3-5, 2013.

Lehmann, A., Hinrichsen, H.-H., Getzlaff, K., and Myrberg, K.: Quantifying the heterogeneity of hypoxic and anoxic areas in the Baltic Sea by a simplified coupled hydrodynamic-oxygen consumption model approach, J. Mar. Syst., 134, 20-28, 2014.

Novotny, K., Liebsch, G., Lehmann, A., and Dietrich, R.: Variability of sea surface heights in the Baltic Sea: an intercomparison of observations and model simulations, Mar. Geod., 29, 113-134, 2006.

Pitkänen, H., Lehtoranta, J., and Räike, A.: Internal nutrient fluxes counteract decreases in external load: the case of the Estuarial Eastern Gulf of Finland, Baltic Sea, Ambio, 30, 194-301, 2001.

Rabalais, N. N., Turner, R. E., Diaz, R. J., and Justic, D.: Global change and eutrophication of coastal waters, ICES J. Mar. Sci., 66, 1528-1537, 2009.

Rheinheimer, G. and Nehring, D.: Meereskunde der Ostsee, Springer, 2nd Edn., 1995.

Rosenberg, R.: Negative oxygen trends in Swedish coastal bottom waters, Mar. Pollut. Bull., 21, 335-339, 1990.

Rudolph, C. and Lehmann, A.: A model-measurements comparison of atmospheric forcing and surface fluxes of the Baltic Sea, Oceanologia, 48, 333-380, 2006.

Sanden, P. and Hakansson, B.: Long-term trends in Secchi depth in the Baltic Sea, Limnol. Oceanogr., 41, 346-351, 1996.

Schreiber, T. and Schmitz, A.: Improved surrogate data for nonlinearity tests, Phys. Rev. Lett., 77, 635-638, 1996.

Sen, P. K.: Estimates of the regression coefficient based on Kendall's Tau, J. Am. Stat. Assoc., 63, 1379-1389, 1968.

Smetacek, V., Bodungen, B.v., Knoppers, B., Peinert, R., Pollehne, F., Stegmann, P., and Zeitzschel, B.: Seasonal stages characterizing the annual cycle of an inshore pelagic system, Rapp. P.v Reun. Cons. int. Explor. Mer, 183, 126-135, 1984.

Smetacek, V.: The annual cycle of Kiel Bight plankton: a long-term analysis, Estuaries, 8, 145-157, 1985.

Tyler, J. E.: The Secchi disc, Limnol. Oceanogr., 13, 1-6, 1968.

UNESCO.: Background Papers and Supporting Data on the International Equation of State of Seawater 1980, UNESCO Technical Papers in Marine Science, 1981.

Wasmund, N. and Uhlig, S.: Phytoplankton trends in the Baltic Sea, J. Mar. Sci., 60, 177-186, 2003.

Wasmund, N., Andrushaitis, A., Lysiak-Pastuszak, E., MüllerKarulis, B., Nausch, G., Neumann, T., Ojaveer, H., Olenina, I., Postel, L., and Witek, Z.: Trophic status of the south-eastern Baltic Sea: a comparison of coastal and open areas, Estuar. Coast. Shelf S., 53, 849-864, 2001. 
Wasmund, N., Tuimala, J., Suikkanen, S., Vandepitte, L., and Kraberg, A.: Long-term trends in phytoplankton composition in the western and central Baltic Sea, J. Mar. Syst., 87, 145-159, 2011.
Welschmeyer, W. A.: Fluorometric analysis of chlorophyll $a$ in the presence of chlorophyll $b$ and pheopigments, Limnol. Oceanogr., 39, 1985-1992, 1994. 